\title{
Success Lies in the Eye of the Beholder: A Quantitative Analysis of the Mismatch Between Perceived and Real IT Project Management Performance
}

\author{
Fabiano G. Neves \\ ESC Rennes \\ fabiano.n.gomes@gmail.com
}

\author{
Hans Borgman \\ University of Amsterdam \\ h.p.borgman@uva.nl
}

\author{
Hauke Heier \\ Accenture Operations \\ hauke.heier@accenture.com
}

\begin{abstract}
Building on an earlier exploratory study, this paper investigates the drivers of the possible mismatch between traditional "real" IT project management performance criteria - quality, time and cost - and "perceived" project management performance. We use partial least squares structural equation modeling to test five main hypotheses with survey data from 248 managers with extensive IT/IS project involvement. The results demonstrate that mismatches between real and perceived project management performance indeed occur. They are predominantly driven by poor expectation management before and during the execution of IT projects, as well as by a low project sponsor commitment. A discussion of the findings and limitations, as well as suggestions for future research, conclude the article.
\end{abstract}

\section{Introduction}

Success and failure of information technology (IT) or information systems (IS) projects and the factors that drive this, are a well-studied topic [14,41]. Despite the wealth of studies and explanatory frameworks, this topic remains elusive. Traditionally, IT/IS project success is assessed based on meeting approved quality (also functionality or scope), time (schedule), and cost parameters, together called the "iron triangle". Measuring iron triangle criteria is viewed as measuring objective or "real" IT/IS project success. Widely adopted project management methods, e.g. [2] and [50], enforce this view: meeting all three criteria implies success, missing all of them implies failure, and some arbitrary middle ground classifies a project as challenged [39]. A 2012 Gartner study found that ontime and within-budget criteria top the list of project performance criteria used by organizations [31].

Given the intrinsic complexity of many IT/IS projects, real (iron triangle) project performance may be difficult to observe, measure, or isolate, and the criteria may change over time. Subjective assessment of IT/IS project success, or "perceived" success, may then come into play and even take over. Perceived performance may also be different from real performance, leading to a mismatch. In such a situation, projects that meet all iron triangle criteria would still be regarded as failures, or, conversely, projects that significantly fall short on these criteria would still be perceived as a success.

This mismatch between real and perceived performance was first studied by Neves et al. [33]. Using data from interviews with 12 senior executives with extensive IT/IS project involvement, they found that this mismatch between real and perceived performance indeed occurs, and explored several factors that could contribute to this mismatch: the quality of expectation management, the client/contractor relationship, organizational politics, senior sponsor commitment and the occurrence of "project fatigue".

The purpose of this current study is to build on and to validate the exploratory model developed by Neves et al. [33], using a quantitative approach. To do so, we will develop a set of testable hypotheses in the next section, after which we will present the research approach, results and discussion.

\section{Literature and Theoretical Background}

\subsection{Challenges to Measuring Performance}

The notion that IT/IS project management performance criteria are less objective than the iron triangle suggests has inspired many authors. While most studies propose alternative success criteria or aim to identify causal links between "success factors" and some measure of project performance, a few studies have investigated which performance criteria are actually used by different stakeholders:

- Project managers: based on a survey among 150 Australian project managers, Collins and Baccarini [13] found that they use the iron triangle criteria as 
well as user and sponsor/client satisfaction as key performance criteria. A next group of somewhat less important criteria include cooperation, organizational goals and stakeholder satisfaction;

- Users: Thakurta [48] looked at the actual users of the system, using multivariate analysis with survey results from 183 Indian users, resulting in a fourdimensional representation of IT project success: a combined "scope and schedule" dimension being the most important determinant explaining over $35 \%$ of the total variance, followed by a dimension related to various project management activities (8\%), a third related to relationship management (5\%) and a last factor representing budget considerations (3\%);

- Senior executives: Liu et al. [28] compared perceptions of risk between top executives and project managers involved in the same project, and found that each group tends to focus on different aspects of risk: senior executives focus more on higher-level risks such as those involving politics, organization structure, process and culture, whereas project managers focus more on lower-level risks such as requirements and user involvement;

- Contractors: Bryde and Robinson [8] compared project performance criteria set by contractors (who emphasize lowering costs and shortening duration) versus clients (who focus on satisfying the needs of other stakeholders), while noting that in the actual project management practice this greater emphasis on stakeholder satisfaction did not exist;

- Other studies have looked at the supplier's perspective [42], and at how different dimensions mean different things to different stakeholders at different times for different projects [44], or at how performance criteria are influenced by stakeholder culture, background and motivational factors as well stakeholder personality [34], [9].

While a large body of literature exists dealing with "real" project management success criteria, the number of publications exploring perception-based criteria is limited. In general, there appears to be an assumption that those are two sides of the same coin. Our review of the literature since 1990, comprising the Senior IS Scholars' Basket of Journals [1], supplemented with the leading (IT/IS) project management journals and (IT/IS) project management tracks in the major conferences (and the related references this review generated) led only to the identification of 41 papers and books covering aspects of perception.

Beyond success criteria, contingencies and stakeholder perspectives, it is important to note that the nature of projects is changing as well. As Weiss et al. point out [49], projects are increasingly spanning functional and organizational boundaries, underlining the importance of the stakeholder perspective. Projects are also increasingly interdependent, making standalone projects (and stand-alone performance evaluation) a thing of the past. Finally, innovative (IT) projects increasingly involve "unknowable" problem parameters and cause-effect relationships, rendering project management in part "best guesswork" which naturally has consequences for performance evaluation [47].

In summary, project management performance is a multi-dimensional construct varying across stakeholders and over time, and influenced by project and environmental characteristics, as well as by organizational and social dynamics. It is not surprising that diverse IT project stakeholders find their own way to assess performance and align their views with the official goals of the project - or not. As a result, perceived project management success will likely play an important role.

\subsection{Research Model and Hypotheses}

Our conceptual research model follows the outcomes of the study by Neves et al. [33]. The dependent variable is the mismatch between real and perceived success, with real success defined as adherence to the iron triangle criteria quality, time and costs, and perceived success defined as the (average) perception of success across the stakeholders.

The exploratory study by Neves et al. found that most interview partners had repeatedly experienced this mismatch. They remarked that several IT projects lasted for many years and blew away any original time and effort estimates but were still regarded as successful, in some cases even as industry showcases. Once completed, the original plans and business cases were not revisited, leading to a form of organizational dementia. To test this, we derive hypothesis HO.a There is a mismatch between "perceived" and "real" IT project success.

Building on this, and assuming that HO.a holds, we hypothesize that the mismatch, if and when it occurs, can take a particular direction. Defining mismatch as the difference between perceived and real success, we can distinguish between an "unjustified hurrah" and an "unjustified malaise". The "unjustified hurrah" occurs when perceived success is higher than real success: the IT initiative's success gets talked up in the light of less positive real results, or even a downright failure. An "unjustified malaise" occurs when, despite a higher score on the "real" iron triangle criteria, perceived project management success is more negative. We then have HO.b - The mismatch can take two directions (unjustified hurrah vs. unjustified malaise).

In addition to these two base hypotheses, HO.a and $H O . b$, we examined five additional hypotheses dealing with the factors that potentially drive the mismatch. 


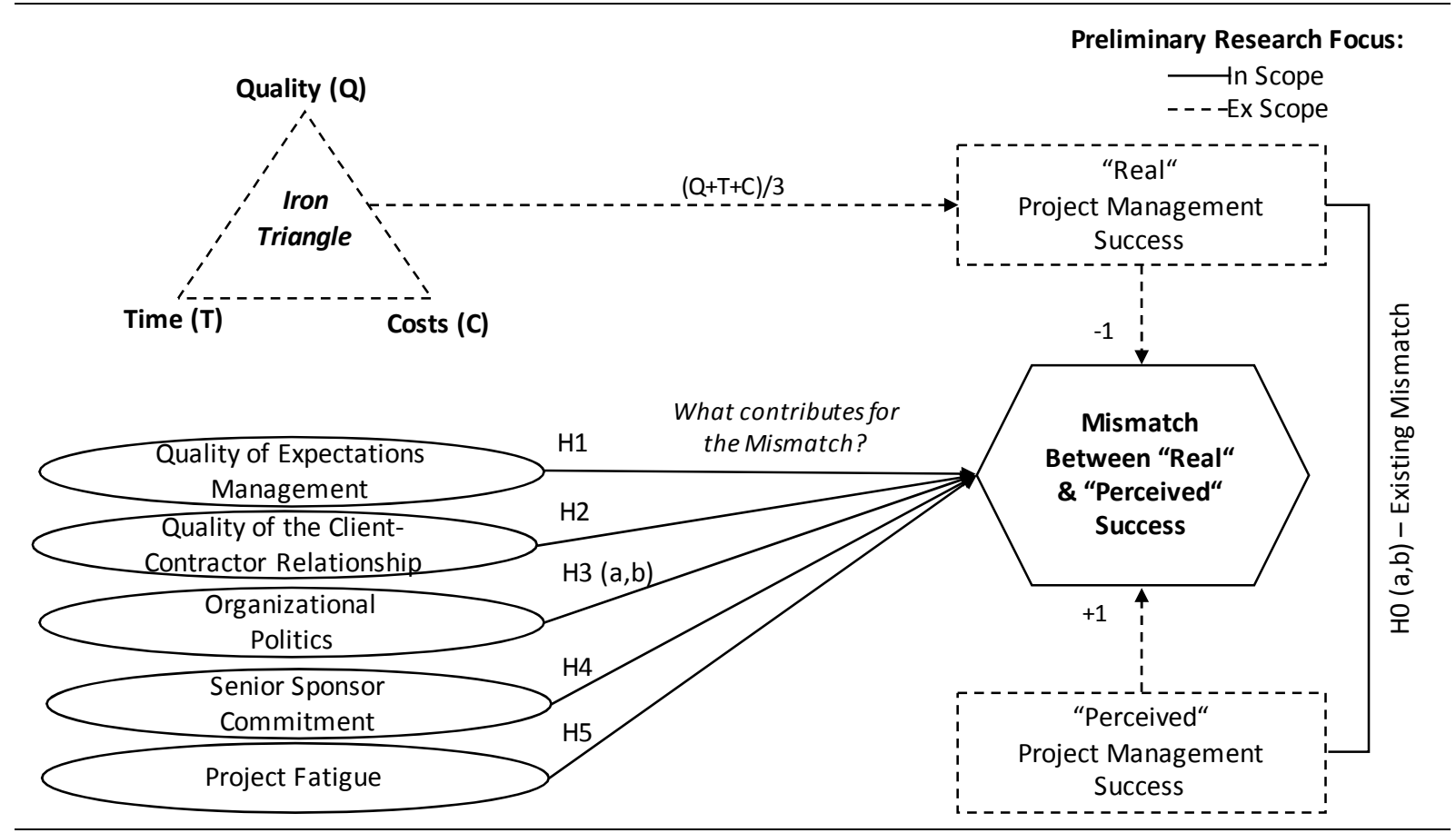

Figure 1. Research Model \& Hypotheses

- Expectation management: Academics and practitioners agree that expectations play a central role in line and project organizations. For the latter, these expectations are normally set at the start of initiatives and comprise iron triangle measurements, as well as more refined metrics for expected benefits or user satisfaction. Expectations should be realistic since Staples et al. [46] found that unrealistically high expectations result in lower levels of perceived benefit than those associated with realistic expectations (i.e. where prior expectations match the actual experience). Related works from Brown et al. [6], Bhattacherjee [4] as well as Petter [37] report on similar findings. This leads to hypothesis H1- The mismatch between perceived and real IT project management success is influenced by the intensity of (realistic) expectation management.

- Client-contractor relationship: A large number of today's complex IT projects in large organizations is executed with the help of external contractors, which adds an important stakeholder group to the project organization and further increases complexity and inherent risk. Project managers need to deal with IT consultant objectives and align these with their own organization and project performance criteria [29]. Pankratz and Loebbecke's study [35] suggests that aligned objectives positively contribute to the success of IT initiatives. This leads to hypothesis $H 2$ - The mismatch between perceived and real IT project management success is influenced by the quality of the client-contractor relationship.

- Organizational politics (a): The study by Neves et. al [33] indicated that organizational politics and power games may have an effect on how project results are achieved and perceived. Organizational politics is defined here as the process by which decisions are made by people, driven by personal and corporate agendas, with room for interpretation and manipulation [30]. Several studies show how subjective/political perspectives can lead to a reframing of IT project performance and to a situation where success is not so much an objective reality but rather constructed by different stakeholders, changing over time, subjectively and arbitrarily [10], [15]. This leads to the formulation of hypothesis H3.a - The mismatch between perceived and real IT project performance is influenced by organizational politics.

- Organizational politics (b): Following Martin [30], we argue that individuals and firms are reluctant to acknowledge project failure, both to avoid sanctions and to conceal the waste of resources. Nobody wants to be associated with failure. In consequence, we postulate that organizational politics will more often occur in combination with an "unjustified hurrah": H3.b - A high level of organizational politics and power games will result in higher mismatch scores 
(perceived performance higher than real performance).

- Senior sponsor commitment: Many studies have demonstrated that active executive engagement, senior management sponsorship and senior sponsorship commitment (these terms are related and sometimes used interchangeably) matter for project success $[17,19]$. This factor does not only matter at project launch time, but also at critical milestones, in situations with roadblocks, setbacks, and problem escalations, and is generally seen as a success factor that can contribute to project success. For our study, we are not looking at project management success per se, but at the mismatch between real and perceived success, and senior sponsor commitment can play a role in this as well, including at the point of project completion. At this point, success is declared or blame is pinned on someone or something, and performance perceptions will likely be influenced positively irrespective of the real project management success. Consequently, we formulate hypotheses $\mathrm{H} 4$ - A higher degree of senior sponsorship commitment will lead to a larger positive mismatch between perceived and real IT project management success ("unjustified hurrah").

- Project fatigue: Projects that last long, either in absolute (years versus months) or relative (longer than planned) terms, can lead to project fatigue, defined here as "a loss of energy and motivation that affects project teams at all levels" [45]. Tired or fatigued stakeholders will lead to reduced commitment, mood swings, and increased frustration. As this fatigue will progressively set in near the end (or planned end) of the project, it will likely have a stronger negative impact on the perceived performance than on the real performance (which may also suffer, but less so), leading to an unjustified malaise. This leads to $\mathrm{H} 5$ - A high level of project fatigue will lead to a larger negative mismatch between perceived and real IT project management success ("unjustified malaise").

Figure 1 presents an overview of the research model and the hypotheses.

\section{Research Approach}

Taking the earlier qualitative study by Neves et al. [33] as a departure point, we constructed a multi-item web questionnaire. Respondents were briefed about the study's purpose in general terms (IT/IS project management success) without reference to the possible mismatch between real and perceived success, and asked to pick a single specific project they had been involved with, and answer all questions with this project in mind. This was done to avoid a sampling bias as well as avoid that respondents would theorize about project management in general rather than offer us the individual data points.

Although both real and perceived performance were outside our research scope (see Figure 1), data on these constructs were collected in order to arrive at a score for our dependent variable, the mismatch between real and perceived project management performance. In our research model, mismatch was calculated as the difference between the perception score and the simple average of the three real performance criteria: quality, cost, and time adherence.

For all 33 questions, a seven-point Likert scale (1-7) was used. To avoid the need to interpolate missing data, all answers were mandatory to submit the questionnaire, except the name of the participant who could opt to stay anonymous. To select participants with senior experiences on IT/IS projects, the researchers selected respondents from their professional network and approached over 4,000 prospective participants by email. An important selection criterion was that no respondent project was completed longer than five years ago nor had a duration below one year. Respondents were also asked to select a project that involved a contractor so we could collect data related to our hypothesis $H 2$.

Participants could have taken any stakeholder role, and since the focus of the study was to analyze mismatch between perception and reality, both successful and unsuccessful projects could be selected. We received 248 (n) answers - indicating a relatively small response rate of $6.2 \%$. All of these answers were loaded into an SPSS [5] (release 23.0.0.0) database where variables were structured in line with our research setup. An analysis of the questionnaire yielded the following demographics of the respondents:

- $83.1 \%$ of the respondents were Brazilians (due to the concentration of contacts from one of the researchers); respondents from other countries included the U.S., Portugal, Argentina, UK, Colombia, Spain, Philippines, India, Mexico, Chile, South Africa, Germany, Italy and China;

- $80.2 \%$ were male;

- $98.8 \%$ had university education, with $63 \%$ having completed a post-graduate education level;

- Average work experience was 21 years, with a mode as well as a median of 20 years;

- $47.6 \%$ ranked as high or top management (e.g. directors, VPs, C-Level, senior managers, board, country managers, etc.) experience and $45.2 \%$ had initial or middle management experience, while the remaining had operational level experience only; 
- Experience on industries indicated an average exposure to 5 different industries (with a mode of 3 and a median of 4 ) throughout reported career.

- The number of people supervised (headcount) was on average 237 people, with a mode of 20 and a median of 50 people.

The demographics show that the respondents were overall very experienced and senior business professionals with access to data on real project success (planned vs actual costs/time/quality) as well as sufficient knowledge to interpret and comprehend project reports, assess stakeholder perceptions of project success and understand corporate politics. Indicators of a normal distribution for the collected variables showed that there were neither strong cases of skewness nor of kurtosis (most absolute values were below 1 and no case above 2 for both distribution shape indicators).

\section{Results}

\subsection{Step one - Factor Analysis}

In order to verify the constructs used in the study, a factor analysis was carried out using SPSS using all constructs mentioned in the research model, including quality, time, and cost as well as perceived success (and not mismatch, which is a calculated value). This resulted in the removal of four items that did not load on the expected factors, possibly due to ambiguous wording. Subsequently, a CFA model was built in AMOS with all constructs (except mismatch). With this modelling it was possible to determine both real success (adherence to planned quality, cost and time) as well as perceived success, in order to calculate the mismatch construct.

The preliminary CFA model we applied shows good construct validity and reliability - with Cronbach Alfas and construct reliability (CR) indices above 0.7 and average variance extracted (AVE) above 0.5 in all cases, as well as good fit indexes [3] including a CFI of 0.944, an RMSEA of 0.057 , a $\chi^{2} / \mathrm{df}$ of 1.798 and an SRMR of 0.055 . This step of the study was conducted mainly to verify that the studied factors "make sense" among themselves and to allow the calculation of the Mismatch construct for further analysis.

In order to check for Common Method Bias (CMB), a Harman's Single Factor Test was conducted, indicating that only $36.3 \%$ of the total variance was explained by a single "forced" factor. Also, a Common Latent Factor (CLF) test [40], with and without a marker variable, was conducted and no standardized regression weight impact higher than 0.2 was detected, thus indicating no relevant $\mathrm{CMB}$ issues.

The calculated mismatch histogram is presented in Figure 2. The data confirms HO.a, ratifying indeed that there is a mismatch between perception and the reality

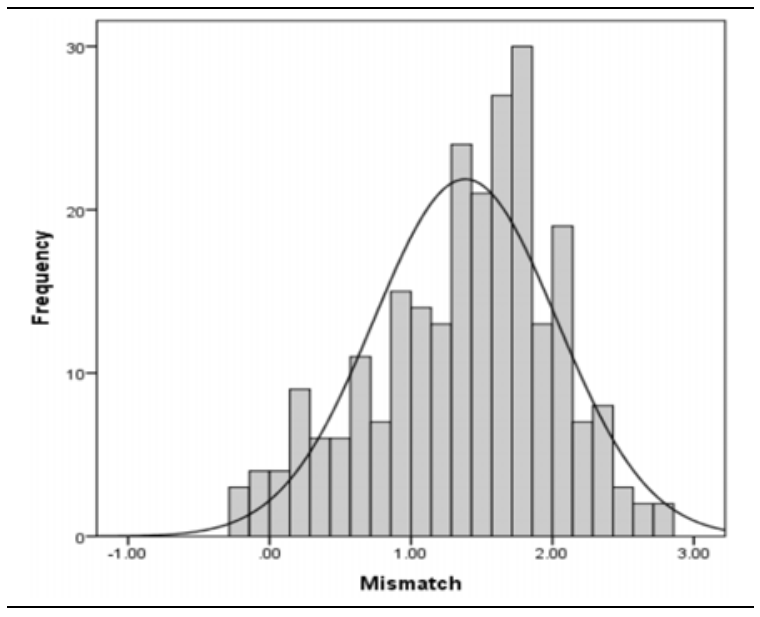

Figure 2. Mismatch Histogram

measured by the iron triangle. Intriguingly it also indicates that our sample predominantly consists of cases with positive mismatch values, so cases where perceived performance is higher than "real" iron triangle performance, an "unjustified hurrah". This will be discussed in greater detail in section 6 .

The occurrence of cases with a negative mismatch value -i.e. an "unjustified malaise"- (however few) does provide support for hypothesis HO.b: that the mismatch can actually take two directions. In these cases, it appears that "objective" iron triangle project management success was talked down and perceived success was lower.

In summary, we have found support for our two-part HO hypothesis, confirming that mismatch is indeed a real phenomenon: perceived and real project management success are related, but distinct constructs.

\subsection{Step two - PLS Analysis}

With the calculated mismatch, it became possible to evaluate the effects of the independent variables / constructs. To execute this second research step with a required degree of flexibility, we selected SmartPLS to perform a Partial Least Squares (PLS) analysis [23]. A traditional PLS analysis presents some limitations (e.g. [22]) which tend to affect value loadings and effects analysis. To mitigate some of these limitations, we used the SmartPLS “consistent PLS algorithm" (PLSc) [16] which corrects PLS simulations making them more similar to (or more "consistent" with) conventional covariance based SEM analysis.

The factors showed good internal consistency reliability (Cronbach alpha, Dijkstra-Henseler's $\rho$ A and CR indexes above 0.7), good convergent validity (Average Variance Extracted $>0.5$ ), good discriminant validity (with the Heterotrait-Monotrait indexes below 


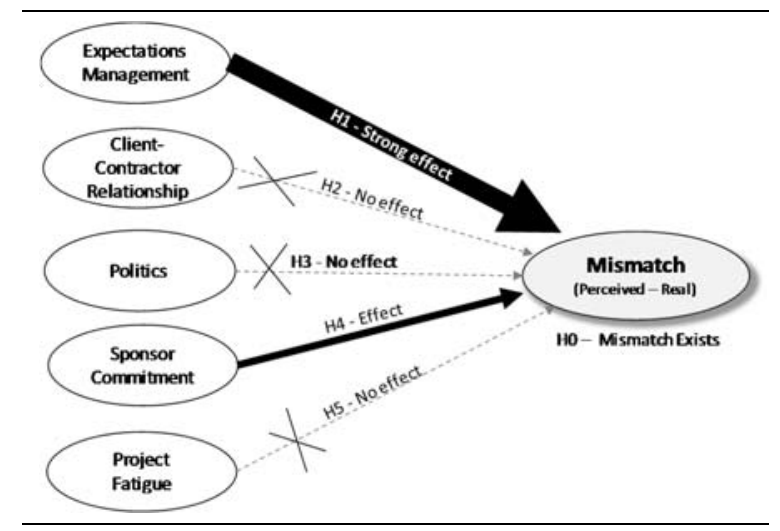

Figure 3. PLSc Model \& Statistical Effects

0.75 [25] and the Fornell-Larcker criterion [18] respected), and no collinearity issues, i.e. having all the Variance Inflation Factors (VIFs) related to Mismatch below 3 .

The statistical model, shown in Figure 3, presented good fit-indexes (as recommended in [24] and [11]), having $\mathrm{SRMR}=0.04, \mathrm{NFI}=0.914$, and reasonable predictive model validity with $\mathrm{Q}^{2}=0.306$ (using an omission distance $\mathrm{D}=7$ ). Also, the coefficient of multiple determination $\left(\mathrm{R}^{2}\right)$ for mismatch was 0.411 , indicating an acceptable level of explanation for the mismatch variance using the studied model.

Table 1 presents the PLSc results considering path coefficients, $p$-values, and Cohen's $\mathrm{f}^{2}$ indicators. The $\mathrm{p}$ values were calculated through a PLSc bootstrapping procedure using 10.000 subsamples. It is interesting to notice that both project fatigue and organizational politics exhibited negative path coefficients - an indication of potential negative influences over the mismatch. As summarized in Figure 3, statistical results indicated a clear and strong effect over the mismatch from expectations management, followed by weaker impact from sponsor commitment - and with no effect detected from either organizational politics, project fatigue or from the client-contractor relationship.

\section{Discussion}

As summarized in Figure 3, statistical results indicated support for two of our advanced hypotheses those analyzing the factors impacting mismatch. There is a strong effect from expectations management, as well as weaker impacts from sponsor commitment. We did not find support for the hypotheses $\mathrm{H} 2, \mathrm{H} 3$ and $\mathrm{H} 5$, i.e. the quality of the client-contractor-relationship, politics or project fatigue influencing the mismatch between real and perceived IT project success.

\subsection{Expectation Management}

IT initiatives are intrinsically complex since they frequently deal with intangible benefits or since their objectives are difficult to conceptualize. They usually involve multiple stakeholder groups, fuzzy expectations (which also change over time), constrained corporate resources (people, money, and time), as well as constant pressure to deliver value/results. Properly executed expectation management can help to avoid disappointment and prevent conflicts; it aligns resource inputs with expected outcomes. These positive aspects will likely improve project success rates and positive success perceptions. In line with earlier literature findings - e.g. [43] - our statistical results show a clear and strong impact of expectations management on mismatch.

A path coefficient of 0.597 and a p-value $<0.001$ indicate a strong significance level. They confirm hypotheses H1- The mismatch between perceived and real IT project management success is influenced by the intensity of (realistic) expectation management. The quantitative results are confirming a finding from the earlier exploratory study [33] where many interview partners pointed out the significance of proper expectation management at the beginning and during the execution of IT projects: "The results, as long as they are properly aligned with expectations and communicated, are the most important thing to consider".

\subsection{Client-Contractor Relationship}

Bryde and Robinson [8] point out the difficulties in aligning the objectives of two key stakeholders groups clients and contractors/service providers. As in any relationship, objectives can be conflicting (e.g. the service provider wants to minimize resource input, the service recipient wants to maximize the iron triangle construct quality), complementary, or congruent (both stakeholders want to finish their initiatives on time). The literature [26] also indicates that the relationship between clients and professional service providers is relevant for avoiding failure but is silent about a potential impact on perceived results. Statistical results did not present evidence that the client-contractor relationship is relevant for explaining a difference between perception and reality.

Similar to what was found in the earlier qualitative study [33], the quantitative findings do not support hypothesis $\mathrm{H} 2$-that a mismatch between perceived and real IT project management success is influenced by the quality of the client/contractor relationship. 


\begin{tabular}{|c|c|c|c|c|}
\hline Construct & \multirow{2}{*}{\begin{tabular}{|c|}
$\begin{array}{c}\text { Path } \\
\text { Coefficient }\end{array}$ \\
$\begin{array}{c}\text { The higher } \\
\text { absolute value, } \\
\text { the higher the } \\
\text { impact. }\end{array}$ \\
\end{tabular}} & \multirow{2}{*}{\begin{tabular}{|l|} 
P-value \\
$p<0.06$
\end{tabular}} & \multirow{2}{*}{\begin{tabular}{|l|}
\multicolumn{1}{|c|}{$\mathbf{f}^{2}$} \\
\end{tabular}} & \multirow[b]{2}{*}{ Summary } \\
\hline Target: & & & & \\
\hline Fatigue & -0.064 & $p>0.15$ & \multicolumn{2}{|c|}{$\begin{array}{l}0.004 \text { No Effect } \\
\end{array}$} \\
\hline Client-Contractor Relationship & 0.012 & $p>0.15$ & \multicolumn{2}{|c|}{\begin{tabular}{|l|l|}
0.000 No Effect \\
\end{tabular}} \\
\hline Expectations Management & 0.597 & $p<0.001$ & \multicolumn{2}{|c|}{0.323 Strong Effect } \\
\hline Sponsor Commitment & 0.213 & $p<0.06$ & \multicolumn{2}{|c|}{0.035 Effect } \\
\hline Politics & -0.205 & $p>0.15$ & \multicolumn{2}{|c|}{\begin{tabular}{|l|l|}
0.026 & No effect \\
\end{tabular}} \\
\hline
\end{tabular}

Table 1. PLSc Results

We hypothesize that the duration of one initiative (or the inclusion of only one project) is probably too short and too small to fully study the impact of a clientcontractor-relationship - a relationship that spans an entire portfolio and many years of cooperation. In addition, this study focused on traditionally executed IT initiatives with a clear distinction between client and contractor roles and waterfall delivery methodologies. Newer, "agile" methods do not emphasize this separation of roles and place the same emphasis on milestones, gates, and pre-agreed outcomes. As these methods are gaining more widespread acceptance, future studies should re-test this hypothesis in more agile settings.

\subsection{Organizational Politics}

According to Gingnell at el. [21], stakeholder politics (with indications that personal or departmental agendas influences decisions to a similar extent than overarching organizational goals) has an impact on the iron triangle outcomes of cost, time, and quality. Our construct for measuring organizational politics in the CFA analysis included only two observable variables ("freedom of communication/interaction" and "unselfish agendas"). Other preliminarily research variables did not offer convergent or statistical validity and therefore were not included in the operational model. The iterative research approach was selected since our literature review did not provide accepted and/or tested constructs as a starting point.

In summary, our statistical analysis did not present significant confirmation for hypothesis H3.a - The mismatch between perceived and real IT project performance is influenced by organizational politics. We speculate that this result may be caused by the intangible nature of politics involving "power games" and results manipulation - things that might either be difficult to observe or where people are less inclined/less able to provide frank evidence. Despite the fact that politics can be something productive [38], the literature suggests [36] that organizational politics can cause employee stress (and ultimately potentially project fatigue, as analyzed with hypothesis H5).

There was only a limited data set to study hypothesis $H 3 . b$ - that the mismatch caused by the presence of organizational politics and power games will result in positive mismatch scores (value $>0.0$ ). With the exception of seven data points we had only data with positive mismatch scores. The data could not confirm a significant positive correlation between those factors. Further studies should revisit the construct of organizational politics in more detail and should probably also rely on constructs from other social sciences disciplines due to an absence of practical frameworks from the information systems literature.

\subsection{Sponsor Commitment}

A wide body of literature (e.g. [7]) emphasizes the relationship between active sponsorship and IT project success. An executive from the previous exploratory study [33] echoed the widely-held belief that "[...] an active and involved sponsor increase the probability of success of a project, but does not guarantee its success. .... The sponsor has to be involved through the entire project life. The lack of a good sponsor causes failures/issues and budget and timeline "bursts"." Committed sponsors can identify and solve problems quickly, help to identify important stakeholders to navigate, and provide organizational alignment and support.

The data collected for our PLSc model confirms hypothesis $\mathrm{H} 4$ - The mismatch between perceived and real IT project management success is influenced by senior sponsorship commitment. Compared to the construct of expectations management, the impact of sponsor commitment was much smaller. We hypothesize that sponsor commitment may be seen as a complementary (and necessary) aspect of expectation management.

Committed project sponsors are always valued by project managers - not only due to organizational power and influence, but also for their experience and coaching capabilities. Another interview partner remarked: "When the sponsor is not close/near to the project, the resources lose empowerment, which in turn affect the general "alignment" and strategic project directives".

\subsection{Project Fatigue}

We did not find statistical evidence for H5 - that a mismatch between perceived and real IT project performance is influenced by project fatigue. While the information systems research literature mentions some aspects related to team fatigue that may affect project 
results, it is more silent related to the potential impacts on perceptions and mismatch. A study on programming [20] indicated that a high amount of overtime increases work team fatigue and in turn the quality of the work delivered.

In line with these findings our research questionnaire initially included items (intended to capture project fatigue) related to team overtime and to the balance between personal life and worktime. These variables did not present reasonable loadings for factor composition and were therefore discarded. We subsequently based fatigue on only a single item (with a focus on team demotivation). This shortcoming should be addressed in future studies to better capture project fatigue.

Hughes et al. [26] and Jettu and Riedel [27] point out that team success depends on attitude, commitment, performance and behavior, and is affected by team composition, trust, respect, turnover, and cooperation. These variables could further impact (team) fatigue and deserve to be studied in more detail.

\section{Conclusion, Limitations and Suggestions for Further Research}

This study tested and extended the earlier qualitative study by Neves et al. [33] on differences between real and perceived IT project management success, using a quantitative approach. The aim was to analyze the divergence between traditional IT project management performance criteria -adherence to functionality, schedule and cost criteria- and perceived project management performance. Our findings should contribute to a better understanding of why and how diverse stakeholder groups judge performance differently, and how this judgement changes over time. The findings illustrate the complexities of performance assessments and how this leaves space for stakeholders to use their own perspective or even push their personal agendas.

Other studies typically investigated a single stakeholder perspective, were based on "iron triangle" performance criteria, and took a single point in time for investigation - typically the project conclusion. In contrast, our study demonstrates that success criteria which are formulated and agreed upon at the start of a project - are hardly objective and change as the project progresses through various phases. The perceived success also depends on the perspective of various stakeholders and project roles, and thus indeed lies in the "eye of the beholder". The statistical results confirm our base hypothesis, as well as two out of our five main hypotheses. Three of the hypotheses did not yield statistically relevant results which might have been caused by an imprecise formulation of a construct.
The conceptual model for project fatigue could benefit from further research and the inclusion of additional/different observed variables to drive up construct validity. Similar to organizational politics, the construct would likely improve by widening the literature review and augmenting the theoretical frameworks with findings from other social sciences disciplines - in particular organizational behavior, psychology, and sociology.

Another limitation of the quantitative study (and its qualitative predecessor) is the concentration of respondent demographics in Latin America (roughly $80 \%$ of study participants). This does not allow for cross-cultural comparisons and/or for eliminating a national culture bias from responses. With only 49 female study participants $(20 \%)$, the impact of gender could not be determined. Further studies should explicitly aim for a better spread to check for crossgender and cross-cultural validity of the presented findings. Alternatively, future researchers could replicate the study with a focus on other countries and groups to allow for direct comparisons.

While we succeeded in confirming the possible occurrence of a mismatch between real and perceived project success, and were able to show that both a positive mismatch ("unjustified hurrah") and a negative mismatch ("unjustified malaise") can occur, we were unable to analyze this distinction in greater detail. With only 7 out of 248 data points related to a negative mismatch or "unjustified malaise" (see Figure 2), we simply did not have the numbers to do so.

It is interesting to consider possible explanations for the overrepresentation of "unjustified hurrah" cases, despite the neutral briefing of the respondents that did not seem to favor a particular sampling bias. First there could be a positivity effect: people favor positive over negative information in their memories, and as perceived performance may ultimately determine how we recall the success of a project, respondents may be more likely to select a project with a high perceived success.

Secondly there could have been a self-serving bias: the fact that we required that respondents had to select a project that they were personally involved in could have led them to select projects that were perceived as successful, following a self-serving bias [12]. Quoting an interviewee from the study by Neves et al. [33]: "People tend to see things in brighter ways when they are directly involved". Thirdly there is the possibility of rosy retrospection, as defined by Mitchell \& Thompson [32], which causes participants to evaluate past events more positively than at the time when an event occurred.

Four factors could contribute to this phenomenon of "rosy retrospection". First, changes in the valuation of specific aspects, in our case "iron triangle" success 
criteria that are incorrectly - and more positively remembered. Second and third, the inclusion of additional factors which did not occur and/or the omission of negative factors which were present at the time of occurrence. Fourth and last, the different weighting of positive aspects and the cost of negative aspects, e.g. being an industry leader with an IT initiative even though it came at the cost of blowing all budgets and timelines (as one of the interview partners in Neves et al. [33] remarked). It would be interesting to repeat this study with an explicit focus on negative mismatch cases, i.e. "unjustified malaise" cases.

Finally, despite the reasonable $\mathrm{R}^{2}$ obtained for the explanations of mismatch by the five main constructs, future research could search for moderators such as change management [26]. Based on earlier studies, we can postulate that this will impact the majority of conceptual models and could further increase the explanatory power of the research framework contributing to an even better understanding of mismatch in the future of information systems research.

\section{References}

[1] AIS. Senior IS Scholars' Basket of Journals. Association for Information Systems, 2014.

https://aisnet.org/?SeniorScholarBasket.

[2] Atkinson, R. Project management: cost, time and quality, two best guesses and a phenomenon, its time to accept other success criteria. International Journal of Project Management 17, 6 (1999), 337-342.

[3] Awang, Z. Validating the Measurement Model: CFA. In A handbook on SEM: Structural equation modelling. 2011, 54-73.

[4] Bhattacherjee, A. Understanding Information Systems Continuance: An Expectation - Confirmation Model. MIS Quarterly 25, 3 (2001), 351-370.

[5] Blunch, N.J. Introduction to Structural Equation Modeling using IBM SPSS Statistics and AMOS. SAGE, 2014.

[6] Brown, S.A., Venkatesh, V., and Goyal, S. Expectation Confirmation in Technology Use. Information Systems Research 23, 2 (2012), 474-487.

[7] Bryde, D. Perceptions of the impact of project sponsorship practices on project success. International Journal of Project Management 26, 8 (2008), 800-809.

[8] Bryde, D.J. and Robinson, L. Client versus contractor perspectives on project success criteria. International Journal of Project Management 23, 8 (2005), 622-629.

[9] Cavarec, Y. Revisiting the Definition of Project Success. PMI Global Congress-North America Proceedings, Project Management Institute (PMI) (2012), 1-9.
[10] Cecez-kecmanovic, D., Kautz, K., and Abrahall, R. Reframing success and failure of information systems: A performative persepective. MIS Quarterly 38, 2 (2014), 561588.

[11] Chin, W.W. The partial least squares approach to structural equation modeling. In G.A. Marcoulides, ed., Modern methods for business research. Lawrence Erlbaum Associates, Inc., 1998, 237-246.

[12] Coleman, M.D. Emotion and the Self-Serving Bias. Current Psychology 30, 4 (2011), 345-354.

[13] Collins, A. and Baccarini, D. Project Success - A Survey. Journal of Construction Research 5, 2 (2004), 211 231.

[14] Dahlberg, T. and Kivijärvi, H. Towards an Integrative , Multilevel Theory for Managing the Direct and Indirect Impacts of IT Project Success Factors. 49th Hawaii Conference on System Sciences, IEEE Computer Society (2016), 4971-4980.

[15] Dhillon, G. Dimensions of power and IS implementation. Information and Management 41, 5 (2004), 635-644.

[16] Dijkstra, T.K. and Henseler, J. Consistent Partial Least Squares Path Modeling. MIS Quarterly 39, 2 (2015), 297316.

[17] Elbanna, A. Top management support in multipleproject environments: an in-practice view. European Journal of Information Systems, 2012, 278-294.

[18] Fornell, C. and Larcker, D.F. Evaluating Structural Equation Models With Unobservable Variables and Measurement Error. Journal of Marketing Research 18, 1 (1981), 39-50.

[19] Fortune, J. and White, D. Framing of project critical success factors by a systems model. International Journal of Project Management 24, 2006, 53-65.

[20] Fryling, M. The Dynamics of ERP Success. 25th International Conference of the System Dynamics Society, (2007).

[21] Gingnell, L., Franke, U., Lagerström, R., Ericsson, E., and Lilliesköld, J. Quantifying Success Factors for IT Projects-An Expert-Based Bayesian Model. Information Systems Management 31, 1 (2014), 21-36.

[22] Goodhue, D.L., Thompson, R., and Lewis, W. Why you shouldn't use PLS: Four reasons to be uneasy about using PLS in analyzing path models. Proceedings of the 46th Hawaii International Conference on System Sciences, IEEE Computer Society (2013), 4739-4748.

[23] Hair, J.F., Hult, G.T.M., Ringle, C.M., and Sarstedt, M. A Primer on Partial Least Squares Structural Equation Modeling (PLS-SEM). SAGE Publications, 2016.

[24] Henseler, J., Hubona, G., and Ray, P.A. Using PLS Path 
Modeling in New Technology Research : Updated Guidelines. Industrial Management \& Data Systems 116, 1 (2016), 2-20.

[25] Henseler, J., Ringle, C.M., and Sarstedt, M. A new criterion for assessing discriminant validity in variance-based structural equation modeling. Journal of the Academy of Marketing Science 43, 1 (2014), 115-135.

[26] Hughes, D.L., Dwivedi, Y.K., Simintiras, A.C., and Rana, N.P. Success and Failure of IS/IT Projects - a State of the Art Analysis and Future Directions. Springer International Publishing, 2016.

[27] Jetu, F.T. and Riedl, R. Determinants of Information Systems and Information Technology Project Team Success : A Literature Review and a Conceptual Model.

Communications of the Association for Information Systems (CAIS) 30, (2012), 455-482.

[28] Liu, S., Zhang, J., Keil, M., and Chen, T. Comparing senior executive and project manager perceptions of IT project risk: a Chinese Delphi study. Information Systems Journal 20, 4 (2009), 319-355.

[29] Luo, W. and Liberatore, M.J. Achieving IT consultant objectives through client project success. Information and Management 46, 5 (2009), 259-266.

[30] Martin, N.A. Project Politics: A Systematic Approach to Managing Complex Relationships. Gower, Surrey, UK, 2011.

[31] Mieritz, L. Stakeholder Satisfaction Is Critical to Determining a Project's Success. Gartner Inc., 2012.

[32] Mitchell, T.R., Thompson, L., Peterson, E., and Cronk, R. Temporal adjustments in the evaluation of events: The rosy view'. Journal of Experimental Social Psychology 33, 4 (1997), 421-448.

[33] Neves, F.G., Borgman, H.P., and Heier, H. Success Lies in the Eye of the Beholder: The Mismatch Between Perceived and Real IT Project Management Performance. 49th Hawaii Conference on System Sciences, IEEE Computer Society (2016), 5878-5887.

[34] Ojiako, U., Chipulu, M., Gardiner, P., et al. Cultural Imperatives in Perceptions of Project Success and Failure. Project Management Institute (PMI), Newtown Square, PA, USA, 2012.

[35] Pankratz, O. and Loebbecke, C. Project Managers' Perception of IS Project Success Factors - A Repertory Grid Investigation. European Conference on Information Systems, (2011), Paper 170.

[36] Perrewé, P.L., Rosen, C.C., and Maslach, C. Organizational Politics and Stress: The Development of a Process Model. In G.R. Ferris and D.C. Treadway, eds., Politics in Organizations: Theory and Research Considerations. Routledge - Taylor \& Francis Group, 2011, 213-255.

[37] Petter, S. Managing user expectations on software projects: Lessons from the trenches. International Journal of Project Management 26, 7 (2008), 700-712.

[38] Pinto, J.K. Understanding the role of politics in successful project management. International Journal of Project Management 18, 2 (2000), 85-91.

[39] PMI. A Guide to the Project Management Body of Knowledge - PMBOK Guide. Project Management Institute, Inc., Newtown Square, PA, USA, 2013.

[40] Podsakoff, P.M., MacKenzie, S.B., and Podsakoff, N.P. Sources of Method Bias in Social Science Research and Recommendations on How to Control It. Annual Review of Psychology 63, (2012), 539-569.

[41] Prabhakar, G.P. What is Project Success: A Literature Review. International Journal of Business and Management 3, 9 (2008), 3-10.

[42] Savolainen, P., Ahonen, J.J., and Richardson, I. Software development project success and failure from the supplier's perspective: A systematic literature review. International Journal of Project Management 30, 4 (2012), 458-469.

[43] Schibi, O. Managing Stakeholders Expectations for Project Success: A Knowledge Integration Framework and Value Focused Approach. J. Ross Publishing, USA, 2013.

[44] Shenhar, A.J., Dvir, D., Levy, O., and Maltz, A.C. Project Success: A Multidimensional Strategic Concept. Long Range Planning 34, 6 (2001), 699-725.

[45] SquarePeg. Addressing Project Fatigue - Re-energising the Senior Project Leadership Team - Case Study. 2011, 1. http://www.squarepeg.com/pdf/CaseStudies/2011addressing-project-fatigue-case-study.pdf.

[46] Staples, D.S., Wong, I., and Seddon, P.B. Having expectations of information systems benefits that match received benefits: does it really matter? Information \& Management 40, 2 (2002), 115-131.

[47] Swan, J., Robertson, M., and Newell, S. Managing the 'Unknowable' in Complex Innovation Projects. Academy of Management Proceedings 2014, 1 (2014), 13549-13549.

[48] Thakurta, R. IS Project Success from Practitioner' $s$ Perspective : Evidences from India. Proceedings of the 48th Hawaii International Conference on System Sciences, (2015), 4397-4405.

[49] Weiss, J., Newell, S., and Swan, J. Introduction to IT / Project Management Minitrack. Proceedings of the 47th hawaii international; conference on system science, (2014), 4275 .

[50] Woodward, H. Beyond Cost, Schedule and Performance: Project Success as the Customer Sees It. PMI Global Congress Proceedings, Project Management Institute (PMI) (2005), 1-6. 